\title{
Cinema, vídeo e videoclipe: relações e narrativas híbridas
}

Paula Faro

Mestranda do Programa de Pós-Graduação em Comunicação e Semiótica da Pontifícia Universidade Católica de São Paulo (PUC-SP)

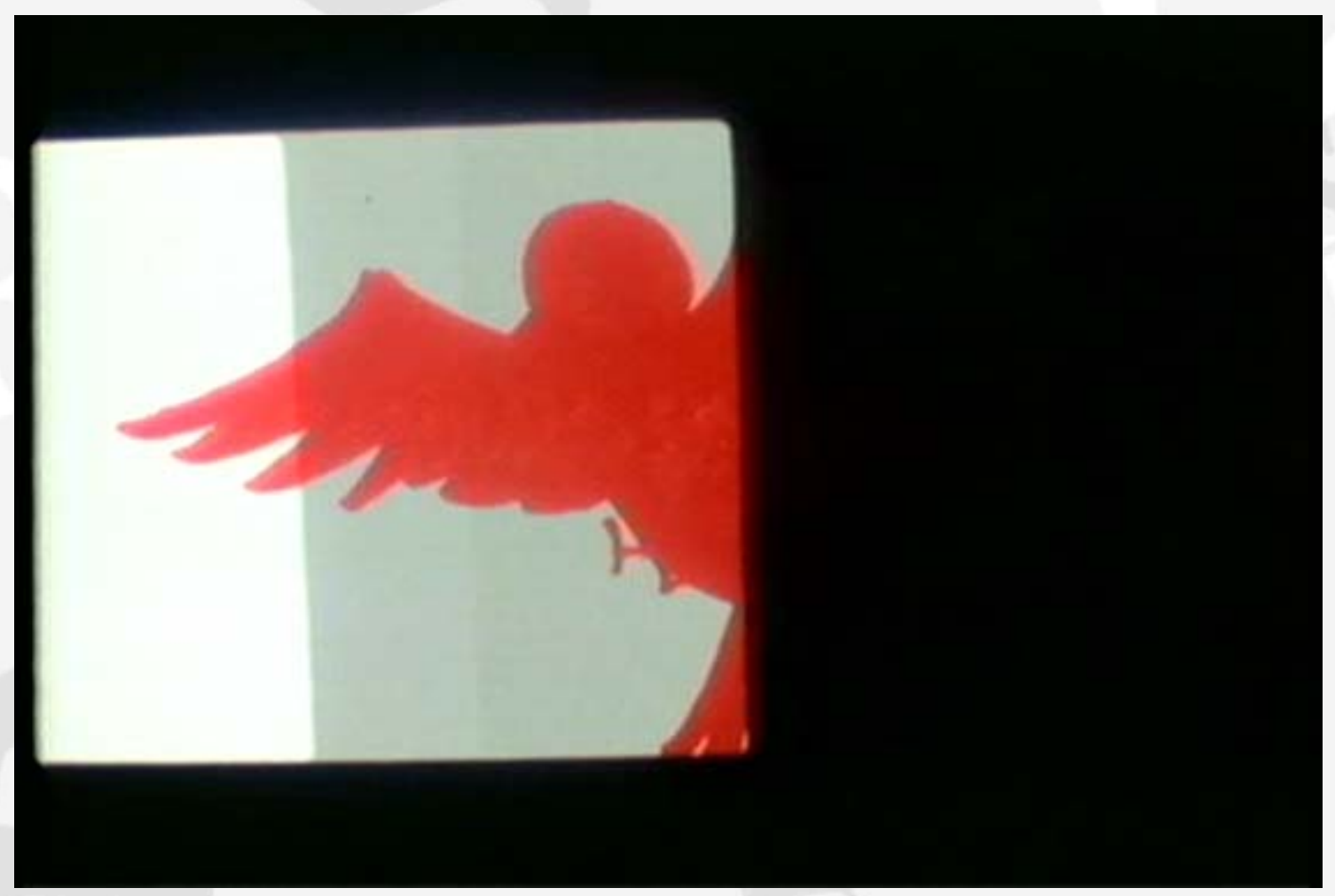

Junior et sa voix d'or (Michel Gondry)

\section{Resumo}

A linguagem do vídeo vem exercendo enorme influência na linguagem cinematográfica, e a relação entre cinema e vídeo tem sido discutida amplamente por diversos autores. A partir dessas discussões, tais como as que Arlindo Machado propõe em Pré-cinemas e pós-cinemas (1997) e em A televisão levada a sério (2001), as de Philippe Dubois, em Cinema, vídeo, Godard (2004), e também as de Raymond Bellour, em Entreimagens (1997), o artigo verifica como a linguagem videográfica aproximou a linguagem do cinema à do videoclipe e vice-versa. Neste contexto, pretendemos analisar o encontro e as relações entre vídeo, videoclipe e cinema, além de identificar os elementos de confluência entre estas linguagens, contribuindo assim para o melhor entendimento dessa tendência contemporânea.

Palavras-chave: Comunicação visual, cinema, hibridismo. 


\begin{abstract}
The language of video has been influencing the language of film; also, the relationship between cinema and video has been discussed by different authors. Based on these discussions, such as Arlindo Machado's Pré-cinemas e pós-cinemas (1997) and A televisão levada a sério (2001), and Philippe Dubois's, in Cinema, video, Godard (2004), as well as Raymond Bellour's, in L'entre-images (1997), the article verifies how the language of video brought together the language of film and the language of music videoclips, and vice versa. In this context we want to analyze the encounter and the relationships between video, music videoclips and cinema. And identify the elements that bring these languages together, contributing to the best understanding of contemporary tendencies.
\end{abstract}

Key-words: Visual communication, cinema, hybridism.

Com o surgimento da televisão e, depois, do vídeo, o cinema começou a ser questionado por esses outros meios de comunicação, assim como também passou a se questionar. A televisão e o vídeo introduziram novos elementos no cinema, mas também tomaram deste diversas características. A existência do diálogo constante entre esses meios, que têm a imagem e o som como elementos fundadores, faz com que nenhum deles se apresente de forma pura, porque existe um movimento constante de intercâmbio que os modifica cada vez mais nos dias de hoje. A linguagem do vídeo vem exercendo uma enorme influência na linguagem cinematográfica. E hoje chegamos a um momento em que existe uma transformação generalizada na forma de concepção, transmissão e recepção do audiovisual. Ou seja, está havendo uma mudança no modo como todos, desde o artista até o espectador, se relacionam com esse meio.

Hoje, a percepção da hibridação entre os meios é dominante, assim como sua dupla potencialização. É essa linha de continuidade que nos interessa. O vídeo aparecendo como potencializador do cinema e vice-versa. Podemos destacar cineastas que, mesmo fazendo cinema, já trabalhavam com princípios (a não linearidade, a colagem, o "direto", a deriva) que se tornariam característicos da videoarte e da linguagem do vídeo. O cinema de Jean Luc Godard ou os procedimentos do cinema direto (para ficarmos nos anos 60) já traziam algumas destas questões, caras ao novo meio e que iriam influenciar fortemente o moderno cinema brasileiro. Uma linha de continuidade entre cinema e vídeo bem mais longa pode ser traçada, principalmente se pensarmos em processos e procedimentos em vez de suportes (BENTES, 2007: 112).

Nesse contexto, o vídeo ocupa um lugar fundamental, já que é um meio pelo qual passam todas estas mudanças. O vídeo como suporte, dispositivo, formato ou linguagem com características expressivas próprias já se estabeleceu no âmbito audiovisual e tem sido amplamente discutido desde suas diversas formas de utilização.

Tanto nas circunstâncias relacionadas à televisão quanto nas circunstâncias relacionadas ao cinema, há em todas essas práticas a presença do vídeo em seu caráter de multiplicidade, descentralidade e 
mutabilidade por conta da desestruturação dos cânones clássicos dessas sintaxes e de suas narrativas. Nessas práticas há também a inscrição de uma linguagem desconcertante, essencialmente híbrida repercutida substancialmente por meio da invenção de novos matizes e saberes para os códigos da arte (MELLO, 2004: 68)

A complexidade apresentada pela linguagem do vídeo nas diferentes formas em que é utilizado proporciona um panorama amplo para perceber como ele vem sendo incorporado no ambiente audiovisual. Configura-se uma rede complexa de interações entre os diversos meios e o vídeo, desde suas relações com diversas linguagens audiovisuais até os vários campos das artes. Christine Mello, em sua tese de doutorado Extremidades do vídeo, trabalha com essas questões, mostrando as relações complexas estabelecidas através do vídeo. Nesse estudo, a autora trabalha o vídeo não em sua totalidade, mas justamente a partir das relações que ele estabelece transformando outras linguagens e sendo por elas transformado, ampliando assim as possibilidades de expressões no audiovisual. Essa característica apresentada pelo vídeo de incorporar elementos de outros meios e ser por eles incorporado, assim como as interferências e conexões que ele permite, constitui um elemento fundamental para pensar o vídeo e suas relações com outros meios. É o caso de sua relação com o cinema e o videoclipe.

O vídeo vive uma proliferação de expressões e impurezas de formas. Por se tratar de um meio heterogêneo, ele tem capacidade de transformar e influenciar as mais variadas manifestações da arte. As contaminações do vídeo dizem respeito às suas infiltrações semióticas nos diferentes campos da estética contemporânea. Neste sentido, é possível afirmar que o vídeo redefine as práticas de arte nas últimas décadas (MELLO, 2004: 137).

O vídeo também veio se apresentando como uma linguagem com características expressivas próprias. A partir de uma análise mais atenta, essas características permitem sua identificação em algumas obras, sejam elas da videoarte, da televisão ou do cinema.

O cinema, a partir de seu surgimento e no decorrer do século XX, veio se estabelecendo como a arte audiovisual por excelência. Com linguagem e características bem definidas, por muito tempo dominou o audiovisual a partir de sua narrativa clássica e linear. O cinema dominante se apresenta como uma organização seqüencial de planos que, em seu encadeamento, encarrega-se de contar uma história com começo, meio e fim. Além desse cinema dominante, vinculado principalmente ao modo de produção industrial, sempre houve um tipo de cinema diferente. Fora do ambiente do cinema clássico, as cinematografias de vanguarda eram ocupadas por realizadores como Georges Méliès ou movimentos estéticos como o expressionismo alemão, a vanguarda francesa e a soviética. Essas eram abordagens da linguagem cinematográfica que se diferenciavam da linguagem clássica. Estes movimentos divergiam do que estava se estabelecendo no sistema industrial com seu aparato tecnológico. Assim como se diferenciavam também e principalmente por apresentarem outra forma de tratar a linguagem cinematográfica e suas possibilidades expressivas. Eram experiências que justamente 
propunham uma forma diversa de usar os elementos que compunham o cinema, que estava se institucionalizando e se sistematizando, tanto em seu aspecto de produção quanto na sua forma narrativa.

Isso que hoje nós chamamos, por exemplo, de a "linguagem" do cinema - um tipo de construção narrativa baseado na linearização do significante icônico, na hierarquização dos recortes de câmera e no papel modelador das regras de continuidade - é o resultado de opções estéticas e de pressões econômicas que se deram na primeira década do século, quando a geração de Griffith surgiu no cenário (MACHADO, 1997: 191).

Durante o desenvolvimento da linguagem cinematográfica, houve grandes mudanças exercidas sobre ela em momentos diferentes. No início da história do cinema, Griffith e outros cineastas estabeleceram os códigos clássicos do discurso cinematográfico. Códigos estes que prevaleceriam no transcorrer da consolidação dessa indústria. Posteriormente, com as vanguardas estéticas mencionadas acima, durante e principalmente depois da Segunda Guerra Mundial, as diversas cinematografias no mundo começaram a romper com o discurso clássico. Estas novas abordagens feitas a partir das vanguardas se apresentavam como outras formas de narrativa, e viriam a estabelecer a linguagem do cinema moderno.

Essas transformações estão relacionadas com diversos aspectos da sociedade: as mudanças socioeconômicas, culturais e, principalmente, a importância que outros meios de comunicação como a TV, o vídeo e, hoje, a internet passaram a ter, exercendo alterações na percepção audiovisual dos indivíduos.

Até os anos sessenta já haviam sido iniciadas diversas rupturas nas cinematografias européias (neorealismo italiano, nouvelle vague francesa, novo cinema alemão). E, posteriormente, isso ocorreu também na norte-americana (Orson Welles, Cassavetes e, mais tarde, nos anos setenta e oitenta, Morrisey, Spielberg, Lucas e Coppola).

\footnotetext{
Apesar de carecermos de recuo, enfim, podemos considerar o período dos anos 80 como uma terceira grande fase histórica: a do pós-vídeo, isto é, aquela em que os efeitos (estéticos) do vídeo estão de tal modo integrados ao filme que acabam constituindo implicitamente a sua base orgânica. Nesse sentido, o cinema contemporâneo teria se transformado, globalmente, em um "efeito vídeo", ou, pelo menos, teria passado por ele, queira ou não, assuma isso ou não, o que explicaria o que certos críticos chamaram, acertadamente, de maneirismo do cinema contemporâneo (DUBOIS, 2004: 182).
}

Com o seu surgimento, o vídeo passou a exercer um papel fundamental nas transformações da narrativa cinematográfica. Na medida em que foi se disseminando, tanto técnica quanto esteticamente, o vídeo foi se incorporando e sendo incorporado por outros meios. A partir dos anos 60, com a videoarte, culminando nos anos 80 , o vídeo foi sendo explorado tanto em seu aspecto técnico quanto em seu aspecto estético. Nos anos 80 o vídeo e o cinema iniciaram um diálogo intenso. A incorporação de características da linguagem do vídeo na linguagem cinematográfica influenciou a narrativa e a lógica do discurso clássico do cinema, transformando-o. 
Quando o vídeo nasceu, já havia incorporado formas de expressão do cinema. A videoarte tomou do cinema características que não estão diretamente relacionadas ao grande discurso estético formalizado pela narrativa clássica vinculada aos formatos industriais. A videoarte incorporou características do cinema vinculadas a outras formas de cinema, como o cinema experimental e as vanguardas estéticas do início do século XX, assim como as que surgiram ao final dos anos cinqüenta e inicio dos anos sessenta, com a nouvelle vaguee as novas cinematografias que estavam nascendo pelo mundo. Era nessas formas narrativas diversas que a videoarte foi buscar elementos que se incorporaram a ela e transformaram-se em uma nova forma de se fazer audiovisual. Assim como o diálogo intenso estabelecido entre a videoarte e as artes plásticas, meio no qual aquela se instalou.

O cinema experimental ou de vanguarda (nenhuma dessas palavras é boa) e a videoarte (que não é melhor) têm em comum essa vontade de escapar por todos os meios possíveis de três coisas: a onipotência da analogia fotográfica, o realismo da representação, o regime de crença da narrativa (BELLOUR, 1997: 176).

O modo industrial cinematográfico e seu discurso clássico estabeleceram-se desde o seu surgimento como espetáculo de massas. A introdução de outras formas expressivas do audiovisual como a televisão e o vídeo vieram trazer novas perspectivas para o cinema, pois quando o vídeo irrompeu, o cinema já estava em um processo de esgotamento. Os cineastas então buscavam novas maneiras de tratá-lo, questionando a relação entre estes meios e sua influência no cinema. Em alguns casos eram inclusive cineastas que já haviam nascido com a televisão e o vídeo, diferentemente daqueles que tinham como referência a literatura, a pintura clássica e o teatro. Um diretor como David Cronenberg, que já havia trabalhado em televisão, fez filmes como "Scanners - Sua mente pode destruir" (1981) e "Videodrome - A síndrome do vídeo" (1983), que, tanto na sua forma como no seu próprio enredo, já dialogavam com o mundo da imagem eletrônica trazida pelo vídeo. Outro exemplo é Peter Greenaway, que veio do ambiente das artes plásticas, principalmente da pintura, e que tem em sua filmografia um amplo trabalho de busca por outras formas narrativas que dialogam diretamente com características da videoarte. Cineastas como Jean-Luc Godard e Michelangelo Antonioni, provenientes da tradição cinematográfica, viram no vídeo e na televisão possibilidades de incorporações e reinvenções a partir da imagem eletrônica. O diretor Michelangelo Antonioni fez "O mistério de Oberwald" em 1981 para o cinema, explorando as possibilidades estéticas do vídeo, pois usou nesse filme o suporte do vídeo para sua realização. Jean-Luc Godard fez diversos trabalhos para a televisão e em vídeo a partir da sua produtora de vídeo independente Sonimage, obras estas que inclusive têm como referência o próprio cinema, como é o caso da série "Histoire(s) du cinéma". Nos anos oitenta, quando o cinema passou a utilizar o vídeo, aconteceram essas incorporações, e os diretores começaram a experimentar com esse outro formato audiovisual, principalmente em seus aspectos estéticos. 


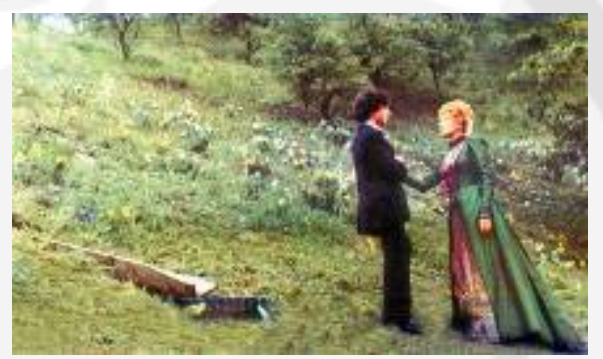

“O mistério de Oberwald”, Michelangelo Antonioni

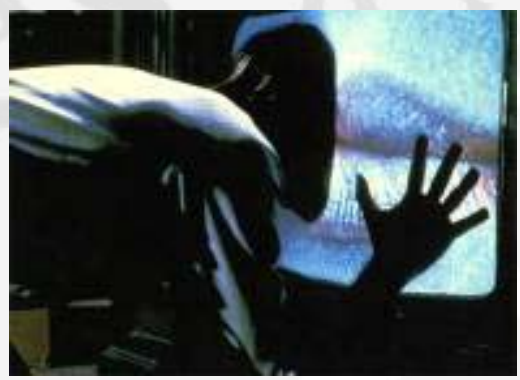

“Videodrome”, David Cronenberg

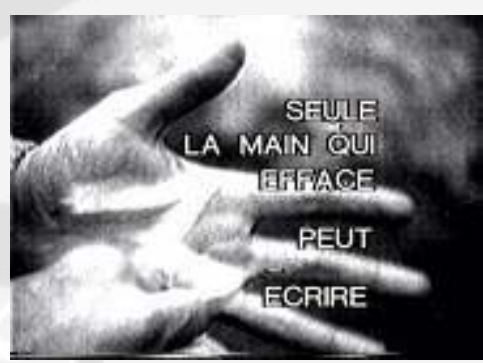

“Histoire(s) du cinéma”, Jean-Luc Godard

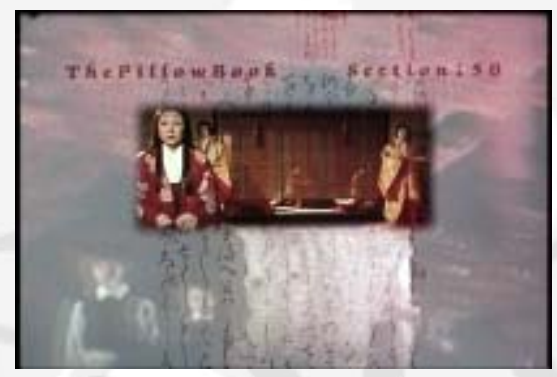

"O livro de cabeceira", Peter Greenaway

Inicialmente, o vídeo foi introduzido no ambiente das artes plásticas e aí se desenvolveu como videoarte, onde foi explorado em seus aspectos de linguagem e formas expressivas e também como dispositivo em videoinstalações. Com as incorporações feitas a partir da videoarte pelo cinema, novas possibilidades de transformações no discurso estético cinematográfico foram realizadas. Os primeiros experimentos no cinema 
com incorporações feitas a partir do vídeo eram modos de fazer cinema que, de certa forma, viam no vídeo uma possibilidade para a exploração de novas características expressivas. Essas incorporações mudariam a lógica narrativa e a linguagem cinematográfica.

O que se caracteriza como cinema ou vídeo? Não são essas reflexões nas quais nos embasamos para essas pesquisas. O que nos interessa não é o formato ou o suporte pelo qual essas obras são veiculadas, mas sim suas estéticas, discursos, linguagens, procedimentos de criação, características poéticas e formas expressivas. É neste lugar que se deu o encontro entre cinema e vídeo.

Assim como a videoarte foi buscar nas vanguardas estéticas e no cinema moderno referências, o cinema pós-vídeo viu na videoarte características que ele passou a incorporar. Isso também se dá em seus aspectos de suporte e tecnologia. É interessante refletir sobre o lugar que o vídeo ocupa hoje no ambiente audiovisual e como, de certa forma, tudo passa por ele, desde o uso doméstico até a internet, passando ainda pela televisão e o cinema.

Os filmes já não são mais filmados utilizando o formato de janela de $35 \mathrm{~mm}$ e, já faz algum tempo, passaram a utilizar outro tamanho de janela, próprio para o enquadramento da televisão. Isso porque se sabe que o filme, depois de ser exibido na sala de cinema (e hoje o tempo que um filme fica em exibição é cada vez menor), será vendido em DVD ou será exibido na televisão. E poderíamos até dizer que hoje as pessoas vêem filmes muito mais na televisão, através da televisão a cabo ou do DVD, do que no cinema. A película, depois de sair da filmagem, é passada para o formato digital e montada em vídeo para depois, apenas quando o filme já estiver finalizado, ser novamente passado para película para sua projeção. Além disso, muitas salas de cinema hoje já incluem em seu aparato de projeção a projeção em vídeo digital. O vídeo vem se tornando o principal meio através do qual a imagem audiovisual é transmitida e recebida, assim como manipulada.

Elementos como o enquadramento e a montagem, a textura da imagem, assim como o ambiente no qual o espectador verá essas obras, são características expressivas importantes no audiovisual. Esses exemplos, que são de ordem técnica, são aspectos que influenciam os procedimentos de criação e incidem sobre a estética da linguagem audiovisual.

As máquinas de bens simbólicos possuem a capacidade de já produzir, em seu próprio interior, uma linguagem específica a elas. Todos nós sabemos, por exemplo, a diferença de se escolher um tipo ou outro de câmera fotográfica, para poder tirar fotografias de uma determinada maneira desejada. Cada câmera, cada jogo de lentes, cada filme possui estruturas simbólicas. Isso representa estruturas de linguagem que, independentemente do que se intenciona criar, já permitem que estejamos em diálogo com uma dada realidade, ou seja, já contêm seus ditames de linguagem a partir da construção de próprio dispositivo. Passamos a perceber que não podemos conceber essas máquinas como um mero suporte na arte. Elas são linguagens mediadoras entre nós e uma percepção do mundo (MELLO, 2004: 39). 
O vídeo ocupa um lugar de passagens, lugar por onde todas as imagens passam, sejam elas do cinema, da televisão, da fotografia, da pintura ou do videoclipe (Bellour, 1997). É nesse lugar, também, que o vídeo veio se incorporando.

O discurso videográfico é impuro por natureza, ele reprocessa formas de expressão colocadas em circulação por outros meios, atribuindo-lhes novos valores, e a sua 'especificidade', se houver, está sobretudo na solução peculiar que ele dá ao problema da síntese de todas essas contribuições (MACHADO, 1997: 190).

Para os autores Richard Grusin e Jay David Bolter, no livro Remediation, nenhum meio supera o outro, mas incorpora os procedimentos do anterior. A media contemporânea, assim como qualquer outra media desde a Renascença - passando pela pintura em perspectiva, fotografia, cinema e televisão, - tem a tendência de incorporar e transformar umas às outras. $\mathrm{O}$ vídeo, seja ele incorporado pelo cinema, pelas artes plásticas através da videoarte e vídeo instalações, na televisão ou na web, possibilita tanto técnica como esteticamente esse processo que os autores conceituam como remediation (1). O vídeo remodela o cinema e as artes plásticas. Assim também como a internet ou o próprio cinema incorporam suas características expressivas remodelandose.

As novas cinematografias ou a ruptura do cinema clássico com o moderno já estavam muito próximas de elementos que podem estar relacionados ao vídeo. Estas incorporações e transformações já estavam sendo feitas, mas o vínculo com o cinema ainda prevalecia. As produções ainda se realizavam com película e as câmeras cinematográficas eram usadas para esses filmes. Elementos como a textura da imagem, a perspectiva, o uso do plano e a montagem ainda eram cinematográficos, mesmo que a relação com a organização da lógica narrativa já tivesse mudado.

Uma das principais características na ruptura entre o cinema clássico e o moderno é a sua relação como o tempo. A narrativa do cinema moderno passou a se dar muito mais em função do tempo do que do espaço. O que implica inevitavelmente que as características cinematográficas ainda estejam inseridas nesses filmes, além de seguirem os modelos de exibição clássicos. Elementos como o plano-seqüência, o branco e preto, a textura e espessura da imagem, perspectiva, profundidade de campo, montagem, travellings e nitidez da imagem são todas características que ainda estavam sendo amplamente usadas pelos cineastas que iniciaram o cinema moderno. Diretores como Alain Resnais, no filme "O ano passado em Marienbad", ou Orson Welles em "A marca da maldade", faziam uso desses elementos característicos do cinema mesmo que estivessem realizando uma profunda mudança na relação da lógica narrativa do filme com o tempo. 


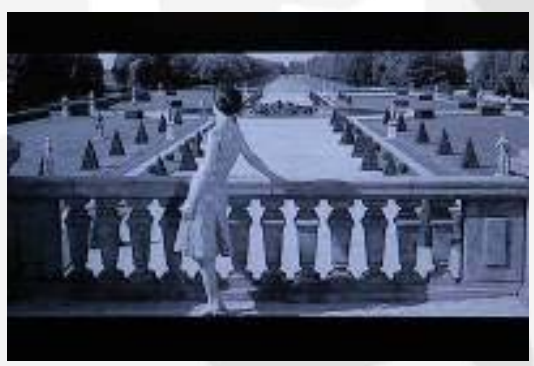

“O ano passado em Marienbad”, Alain Resnais
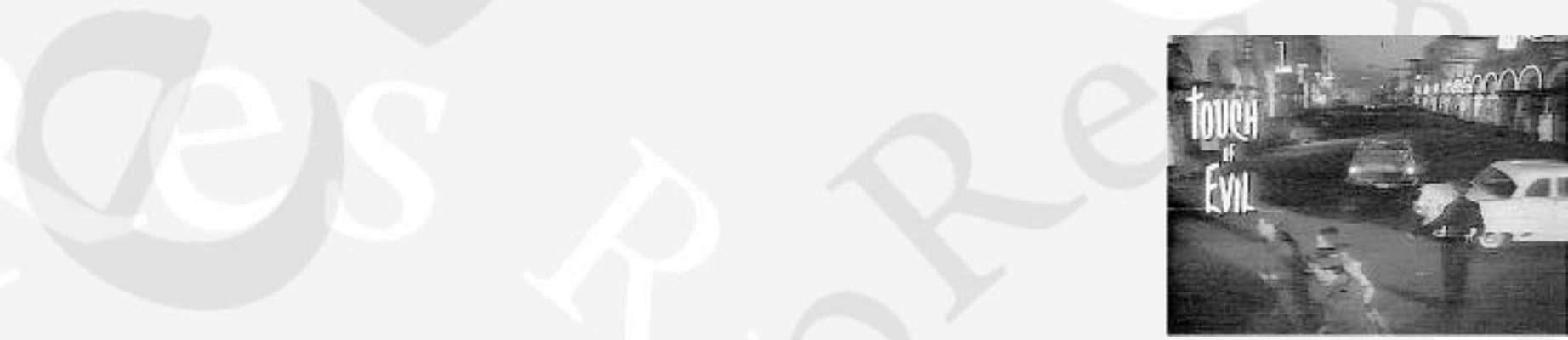

“A marca da maldade”, Orson Welles

Para Deleuze, a ruptura entre o cinema clássico e o moderno se dá em função da relação da organização lógica da narrativa com o tempo. Nas novas cinematografias também já havia muitas experiências em relação à montagem ou até mesmo antes, com cineastas como Dziga Vertov e Sergei Eisenstein, onde a noção de montagem era fundamental para a concepção de seus filmes. Diretores como Jean-Luc Godard e Alain Resnais também consideravam a montagem um dos principais procedimentos da linguagem cinematográfica. Essa relação tempo/espaço é um fator constituinte da narrativa clássica. E a linguagem cinematográfica estabelecida a partir de Griffith era uma linguagem voltada para a noção espacial do plano e também da história e da ação dos personagens. Uma cena ou um plano geralmente definia-se em função do espaço.

À escala "homogenista" dos planos, opticamente hierarquizante e filosoficamente humanista do cinema, a videoincrustração opõe assim um principio de composição plástica em que as relações espaciais são ao mesmo tempo fragmentadas e achatadas, tratadas sob modos discursivos, mais abstratos ou simbólicos do que perceptivos, escapando a toda determinação óptica que seria concebida a partir de um ponto de vista único estruturador da totalidade do espaço da imagem (DUBOIS, 2004: 85).

Quando um personagem mudava de ambiente, mudava-se a cena. Ou a mudança de plano ocorria para afastar-nos ou aproximar-nos do objeto que estávamos vendo, em relação ao espaço. Com o tempo, a técnica e a tecnologia no cinema foram possibilitando o desprendimento desse espaço com câmeras mais leves, películas mais sensíveis e objetivas mais aprimoradas. Assim, o caráter espacial foi perdendo seu foco e a ruptura do cinema moderno com o clássico deu-se a partir da relação que os novos realizadores tinham com o tempo da imagem e sua lógica temporal, muito mais do que sua lógica espacial. Além de começarem a questionar e a 
pensar a linguagem e a estética cinematográfica desde outro ponto de vista que não aquele do discurso da transparência com um determinado fim. Nesse caso, quando se fala de tempo no cinema, a montagem é um fator determinante.

A montagem ou, no caso do vídeo, como nomeia Philippe Dubois, a mixagem de imagens, é uma das principais mudanças na relação vídeo e cinema. A partir das construções poéticas e de procedimentos de criação, como a montagem e a planificação no cinema, e a mixagem de imagens e a imagem no vídeo é que se dão as incorporações entre cinema e vídeo. O vídeo não como dispositivo, sinal, ou um simples meio por onde se transmitem imagens, mas o vídeo como uma estética, como um modo de fazer audiovisual em sua relação a partir deste aspecto.

A diferença nessa relação entre cinema e vídeo acontece na forma como estes construíram seus discursos a partir de incorporações feitas desde suas construções poéticas e procedimentos de criação, apesar de todas as diferenças técnicas e tecnológicas implicadas.

O cinema estabeleceu-se como linguagem a partir de uma narrativa clássica linear voltada para a ficção. O vídeo, predominantemente, quando utilizado como linguagem, não procedeu dessa forma. Mas sim muito mais a partir de seus aspectos plásticos, que remetem a uma procura por outra construção poética, para criar outros sentidos, a partir de uma lógica que não necessariamente se dá como uma narrativa e ficção. $\mathrm{O}$ vídeo foi amplamente utilizado no âmbito das artes plásticas e só depois foi incorporado ao cinema, a partir dos anos oitenta. Essa interferência deu-se na obra de uma série de diretores como David Cronenberg, Michelangelo Antonioni, Jean-Luc Godard, Win Wenders, Peter Greenaway, Francis Ford Coppola e depois, nos anos noventa, Lars Von Trier, David Lynch e Larry Clark, para citar alguns. Esses realizadores viam no vídeo uma possibilidade de fazer cinema de uma forma divergente do que a estabelecida pelo contexto hollywoodiano. O vídeo começou a ser incorporado pelo cinema através de criadores que experimentavam essa nova linguagem a partir de sua possibilidade de desestruturar e romper a narrativa clássica estabelecida pela indústria cinematográfica.

(...) é possível observar também o modo como o cinema é afetado ao ser desconstruído pelos criadores que utilizam o vídeo digital, gerando, portanto, um novo cinema (MELLO, 2004: 68).

O vídeo cresceu muito mais a partir de explorações plásticas e também em seu caráter documental. Ele não se estabeleceu como uma linguagem institucionalizada, como aconteceu no cinema, e sim a partir desse lugar de passagens entre imagens. E é porque o vídeo não se estabeleceu como tal que possibilita as transformações estéticas ou as interferências e reapropriações. Assim, o vídeo possibilita uma liberdade nos seus modos de criação, como também permite que o cinema seja revisto por ele. Como é o caso do vídeo “Love stories”, realizado por Lucas Bambozzi em 1992. Nesse vídeo, o artista, a partir de um fotograma do 
filme "Hiroshima mon amour", de Alain Resnais, constrói seu trabalho sobre relações amorosas, recriando o significado original da imagem do filme (2). Também o caso de Jean-Luc Godard com a série "Histoire(s) du cinéma", uma reflexão sobre a história do cinema feita através do vídeo. O vídeo ocupa um lugar de passagens, entre-imagens, processo e estado, regido a partir de uma lógica temporal, por onde todas as imagens transitam.

\begin{abstract}
A imagem completa, o quadro videográfico, já não existe no espaço, mas na duração de uma varredura completa da tela, portanto, no tempo. A imagem eletrônica já não é, como eram todas as imagens anteriores, ocupação da topografia de um quadro, mas síntese temporal de um conjunto de formas em mutação (MACHADO, 1993: 52).
\end{abstract}

Dentro de suas características, diferentemente do cinema, o vídeo não utiliza elementos tais como a perspectiva e a profundidade de campo. No vídeo constrói-se uma lógica temporal que não é necessariamente narrativa. Ao contrário do cinema, que trabalha com planos, o vídeo cria imagens com um tipo de enquadramento articulado por outros princípios que não os da perspectiva e da relação espacial.

O plano, o enquadramento e a montagem são fundamentais para a construção da narrativa no cinema. Esses são os meios pelos quais um realizador ou diretor constrói a estética e organiza seu filme, dando sentido e significado para ele. Esses elementos são modificados quando utilizados pelo vídeo para outro fim, buscando sentidos e significados distintos. Plano, enquadramento e montagem no cinema e no vídeo têm abordagens distintas e são utilizados de formas diferentes: “À noção de plano, espaço unitário e homogêneo, o vídeo prefere a de imagem, espaço multiplicável e heterogêneo" (DUBOIS, 2004: 84).

Outros elementos que são característicos da composição estética da imagem audiovisual e que diferem na relação entre cinema e vídeo são a plasticidade e a textura da imagem, a organização dos planos ou das imagens no caso do vídeo, o efeito narrativo e o tempo. Philipe Dubois nomeia alguns dos procedimentos de criação que voltaram ao cinema depois que o vídeo foi incorporado a ele: câmera lenta, imagem congelada, revalorização da sobreimpressão, gosto pela imagem dividida, multiplicada, incrustada, deformações óticas ou cromáticas, referência visual às outras artes, como a música e a pintura e a própria história do cinema.

Essas transformações que foram se desenvolvendo nos anos oitenta, quando diversos cineastas fizeram seus experimentos com o vídeo e também com a televisão, acarretaram uma mudança profunda no contexto audiovisual. A partir dos anos noventa a relação entre cinema e vídeo já havia saído do seu ponto inicial e, à medida que novos realizadores apareciam, outros meios eram inseridos nesse contexto, como foi o caso do videoclipe.

O videoclipe possibilita que estas incorporações e conexões entre os diversos meios sejam feitas. Ele apresenta características de linguagem que provêm do videoarte, do cinema, assim também como de outros campos da arte. Arlindo Machado fala das características da imagem eletrônica enquanto sistema de expressão. 
As anamorfoses e dissoluções de figuras, os imbricamentos de imagens umas nas outras, as inserções de textos escritos sobre as imagens, os efeitos de edição ou de collage, os jogos das metáforas e das metonímias, a síntese direta da imagem no computador não são meros artifícios de valor decorativo; eles constituem, antes, os elementos de articulação do vídeo enquanto um sistema de expressão (MACHADO, 2007: 30).

$\mathrm{Na}$ obra de Michel Gondry, podemos ver alguns exemplos em seus videoclipes. O diretor reconfigura expressões do cinema, da videoarte, das artes plásticas, do teatro e do videogame e incorpora em sua obra elementos de linguagem desses meios, ressignificando seus procedimentos de criação. Um exemplo da referência ao cinema nos procedimentos de criação é o uso da animação quadro a quadro, como a animação com desenhos ou bonecos de plastilina. Efeitos que nos fazem lembrar tanto o cinema de animação de Norman McLaren como os efeitos do cinema de Georges Méliès. Inserção de elementos da videoarte ou do próprio vídeo como o uso do efeito caleidoscópio, solarização, chromakey, inscrustração, sobreposição de imagens e alterações na velocidade da imagem. No videoclipe "Let forever be", por exemplo, o diretor utiliza o próprio suporte vídeo para uma parte e película para a outra, diferentemente da maioria dos clipes filmados inteiramente com película. Isso traz para a imagem uma textura diferente daquela característica da película cinematográfica. Inclusive nesse trabalho, o diretor faz todo um jogo de construção da imagem a partir da estética do vídeo utilizando diversas construções poéticas características desse meio.
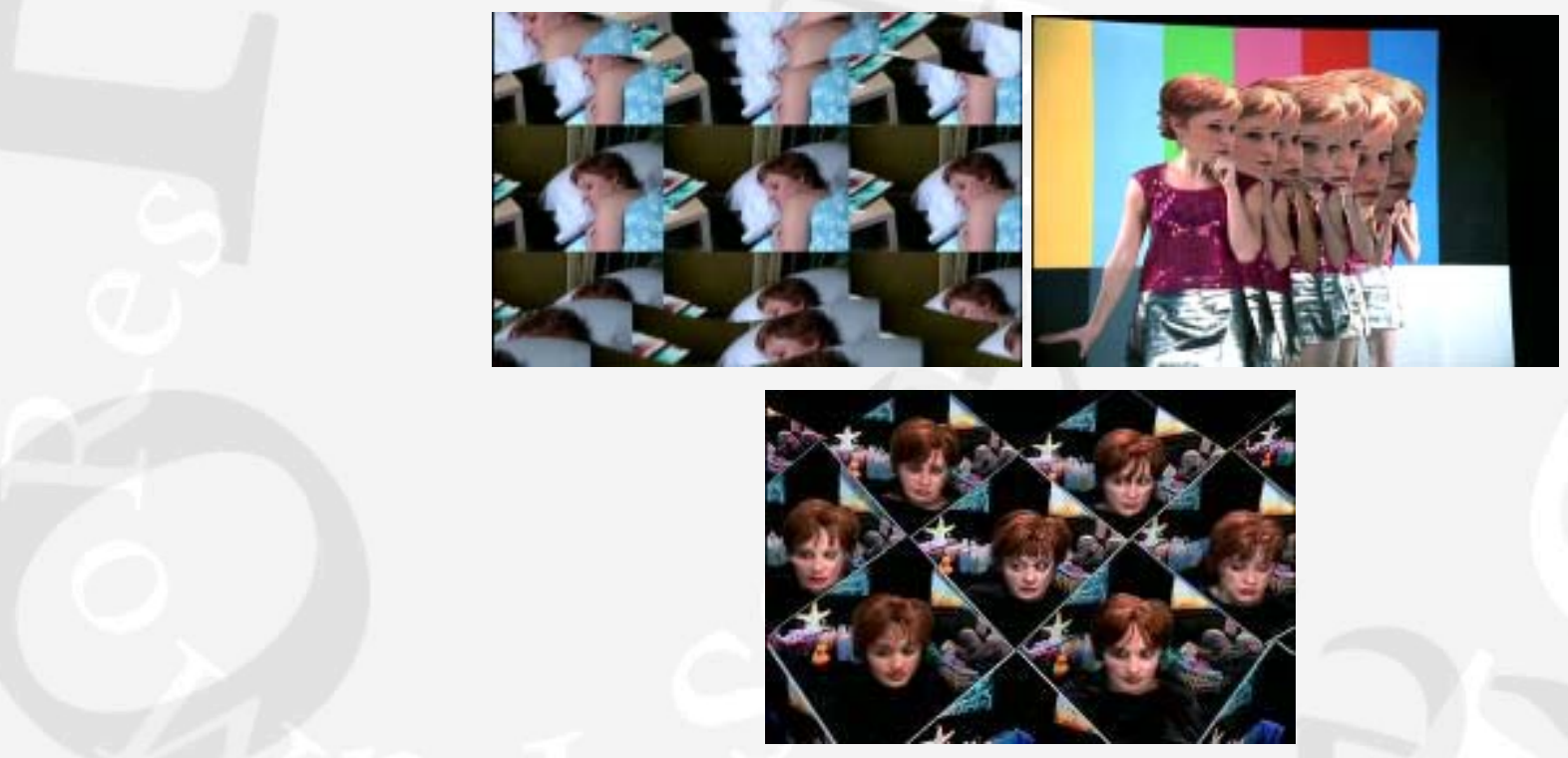

"Let forever be", Michel Gondry 


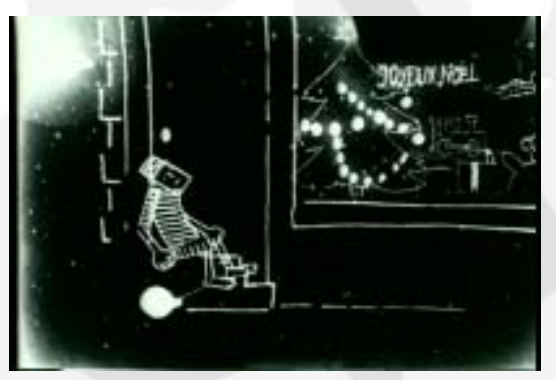

“Joyeux Noel”, Michel Gondry

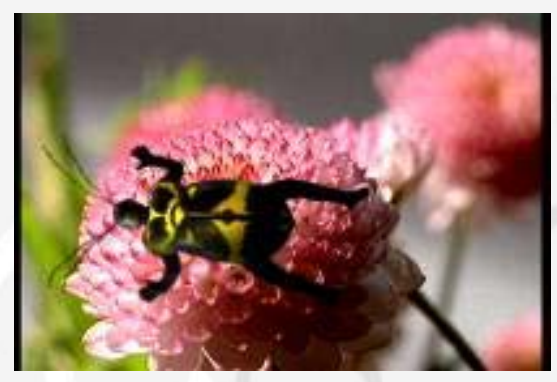

“Ma maison”, Michel Gondry

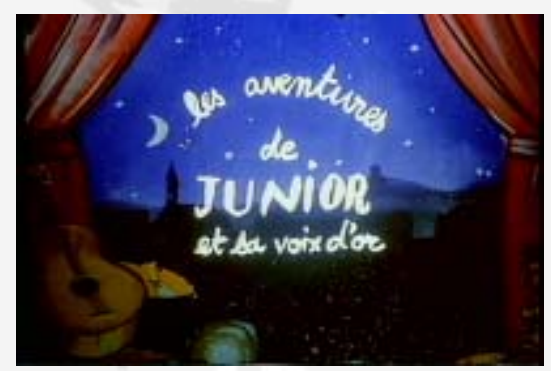

“Junior et sa voix d'or”, Michel Gondry

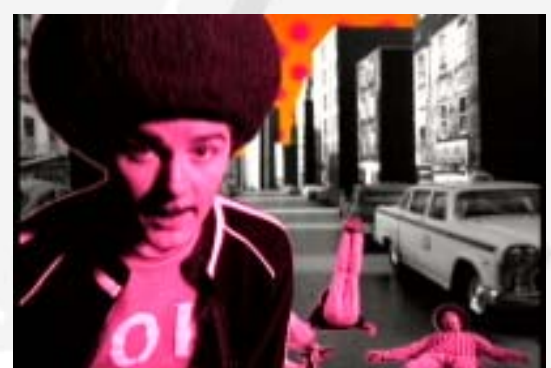

"La ville", Michel Gondry

Muito relacionado à videoarte e também ao cinema experimental, a linguagem do videoclipe foi sendo desenvolvida tanto por cineastas que já haviam feito cinema e depois foram fazer videoclipe, como também por diretores que nunca haviam feito cinema ou vídeo. Esses diretores foram fazer videoclipe e acrescentaram a ele experimentações que incorporavam tanto elementos do cinema como da videoarte. 
O videoclipe, a partir dessas incorporações tanto do cinema como do vídeo, tornou-se um lugar para esses realizadores que em alguns casos fazem apenas videoclipes. Assim como o vídeo e o cinema, o videoclipe tem características expressivas que foram se tornando próprias a partir de transformações e incorporações tanto de elementos do cinema como do vídeo.

Um elemento importante para pensarmos o videoclipe é ver de onde seus principais artistas vieram e também o fato de eles não trabalharem apenas com um meio, mas transitarem por diversos como a fotografia, a publicidade, o cinema, a televisão, a música e as artes plásticas. Como, por exemplo, o diretor Chris Cunningham, que iniciou sua carreira com as artes plásticas e com a videoarte. É também o caso de Anton Corbijn, que se originou como fotógrafo e fez seu primeiro longa metragem, "Control", filme que trata da história de Ian Curtis, o vocalista do grupo Joy Division, lançado em 2007. O diretor Jonathan Glazer também passou do videoclipe ao cinema e fez filmes como "Sexy beast" (2000) e "Birth" (2004). Mark Romanek estreou no cinema com o filme "Retratos de uma obsessão" (2002), após ter feito diversos videoclipes. O diretor Stéphane Sednaoui também teve sua carreira iniciada com a fotografia. É também o caso de Spike Jonze, que fez uma carreira profícua no videoclipe para depois fazer cinema com filmes como “Quero ser John Malcovich" (1999) e "Adaptação" (2002). Todos os nomes citados acima são exemplos de realizadores que vêm se afirmando no videoclipe pela qualidade de seus vídeos, trabalhos estes considerados como obras importantes nesse meio, por seus aspectos de linguagem e formas expressivas. Esses diretores e seus trabalhos também são considerados importantes por sua inventividade no formato do videoclipe. Na sua maioria, eles não vieram do cinema, mas sim de outros meios, como a fotografia, a videoarte, as artes plásticas, a música - e posteriormente foram fazer videoclipes. A interação entre as estruturas de linguagens desses diferentes meios foi incorporada ao videoclipe, gerando novos significados.

O videoclipe deixou de ser apenas um vídeo promocional para a indústria musical. Nele eram mostrados apenas os cantores e as bandas fazendo suas performances na frente da câmera, aparecendo durante o vídeo inteiro. O videoclipe passou a ser considerado uma obra audiovisual com características bastante expressivas. No texto a Reinvenção do videoclipe, Arlindo Machado propõe uma reflexão sobre o videoclipe como um novo espaço audiovisual de onde surgem novas propostas de construções de linguagem e expressões poéticas. Essas novas experimentações estariam ligadas tanto ao cinema de vanguarda dos anos 20 como ao cinema experimental dos anos 50 e 60 e à videoarte dos anos 60 e 70. Arlindo Machado analisa, a partir dessa proposta, o videoclipe como uma forma de onde derivam várias tendências que possibilitam sua redefinição, revelando diversas características estilísticas próprias desse meio, que validam seu lugar dentro do plano do audiovisual como um novo campo de expressão.

A mostra Comunismo da forma: som, imagem, tempo. A estratégia do vídeo musical (3), que ocorreu em São Paulo em 2007, é um exemplo de como o videoclipe vem se estabelecendo no ambiente audiovisual. 
Essa mostra, assim como o blog e o livro vinculados a ela, é um projeto que pretende olhar e pesquisar o videoclipe dentro do ambiente da arte e como uma manifestação cultural contemporânea.

Aqueles diretores trouxeram experimentações para o videoclipe a partir de diversos elementos, incorporando características expressivas para a construção de uma linguagem que não mais fazia do videoclipe uma seqüência de imagens ilustrativas da música.

É o caso, por exemplo, do clipe “A song for the lovers”, dirigido por Jonathan Glazer. Nesse trabalho, vemos pouquíssimos cortes, quase um plano seqüência, uma única cena com um único cenário, onde existem longos momentos de silêncio, além de um diálogo que interrompe a música durante o vídeo. O personagem liga e desliga a música quando quer. Um jogo de cena entre a música e o silêncio, onde o personagem escuta a música no rádio enquanto se arruma e come.

O processo de realização do videoclipe tornou-se mais sofisticado tanto na produção como no uso dos procedimentos de criação que antes não eram utilizados por esse meio. Os efeitos especiais realizados na pósprodução e os efeitos de edição característicos do vídeo, como o reverse, a alteração na velocidade da imagem, a sobreposição de imagem, o chromakey, assim como a criação de histórias e personagens que fogem à necessidade figurativa de caráter narrativo do cinema são alguns exemplos. $\mathrm{O}$ videoclipe se apresenta com características muito mais plásticas e rítmicas, assim como com a tendência a uma organização não linear dos planos para criar seu universo.

O clipe, com sua ausência de hierarquia entre o velho e novo, o tecnológico e o artesanal, coloca em movimento todo o repertório da 'biblioteca' (4) que, ao encontrar a memória, a nostalgia e os estados emocionais dos espectadores, ganha um novo corpo, um novo significado e um novo contexto a partir de seus três elementos formadores: o som, a imagem e o tempo, criando na cultura de massa e para a cultura de massa (OLIVA e REZENDE, 2007: 11).

Outro elemento importante é a busca por um tratamento da textura da imagem através de recursos fotográficos como o uso de um tipo de iluminação que busca ressaltar a plasticidade da imagem. O uso de processos inversos aos que são geralmente utilizados pelas formas tradicionais e profissionais da indústria também fazem parte de seus procedimentos de criação, como trabalhar com películas de 8mm e 16mm e depois fazer diversos tipos de processamentos nos laboratórios para criar inúmeras formas de rasuras e marcas na imagem. Características como imagem muito granulada, o branco e preto, cores muito fortes e contrastantes, fotografia estourada, são alguns procedimentos utilizados no videoclipe, como na obra de Anton Corbjin e Stephane Sednaoui. Estão presentes construções poéticas como: distorções, desintegração das formas, instabilidade dos enunciados, anamorfose e dissolução de figuras, inserção de texto escrito, collage e abstração como recurso formal (MACHADO, 2007). E, com a crescente possibilidade tecnológica, muitos videoclipes se caracterizam por seus efeitos especiais realizados em pós-produção. O videoclipe também trabalha com um modo de representação diferente daquele proveniente da fotografia, do cinema ou da pintura clássica, 
figurativa, realista ou documental. Procedimentos estes muito característicos da videoarte e do cinema experimental.

A relação com o cinema no universo do videoclipe se dá não somente a partir de seus aspectos de linguagem, características expressivas e aparato técnico, mas também faz referência ao imaginário cinematográfico. Alguns casos são os vídeos de Spike Jonze "It's oh so quiet", onde vemos uma referência aos musicais dos anos 40, e também "Sabotage", que nos faz lembrar um filme policial dos anos 70. Outro exemplo é o videoclipe dirigido por Jonathan Glazer, "Karmacoma", referência ao filme "O iluminado", de Stanley Kubrick.

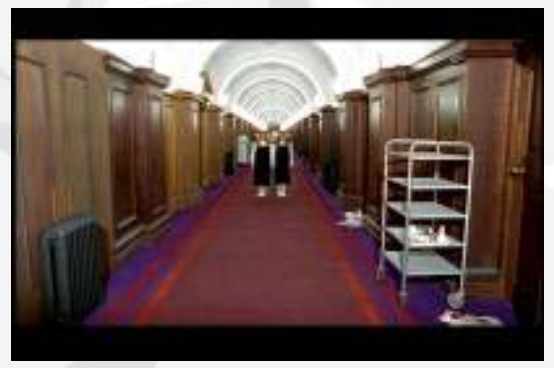

“Karmacoma”, Jonathan Glazer

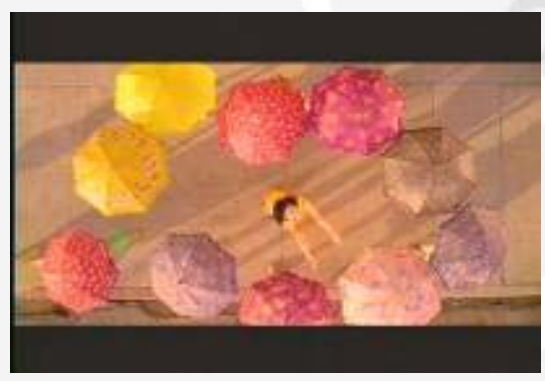

"It's oh so quiet”, Spike Jonze

Um realizador que marca bastante seus vídeos com o uso de efeitos especiais para criar todo um universo e personagens bastante particulares para cada um de seus trabalhos é Chris Cunningham. Assim como Michel Gondry, ele se caracteriza por criar um universo lúdico, passando pelo diálogo intenso com as artes plásticas, os jogos, o videogame e o cinema para criar seus trabalhos. 


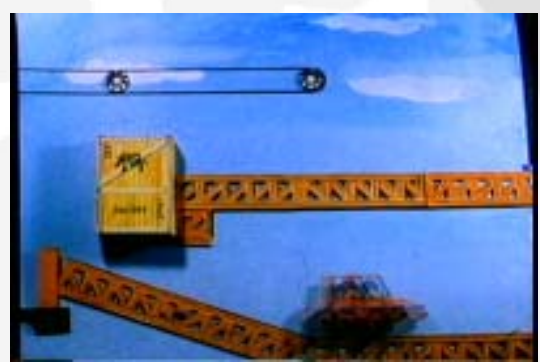

“Bólide”, Michel Gondry

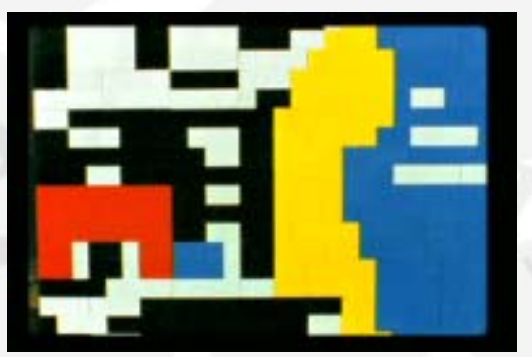

"Fell in love with a girl”, Michel Gondry

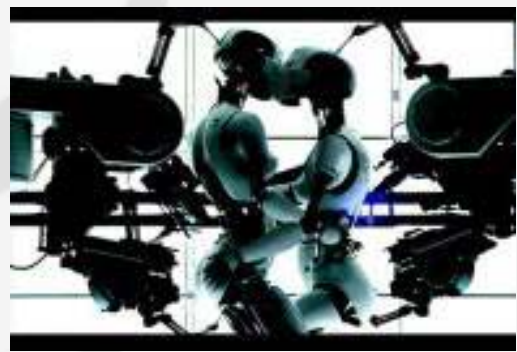

"All is full of love”, Chris Cunningham

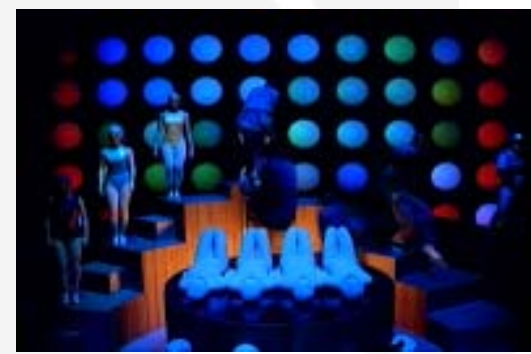

"Around the world”, Michel Gondry

É interessante notar que esses diretores realizaram seus trabalhos em videoclipe com músicos que também são considerados muito inventivos dentro do ambiente da música, como é o caso de Björk, Aphex Twin, Portishead, Radiohead, Red Hot Chilli Peppers, Joy Division, Massive Attack, Nine Inch Nails, Fatboy Slim, Beastie Boys, Chemical Brothers, The White Stripes e outros.

A relação entre os diretores e as bandas ou cantores se transforma em uma parceria autoral. Esses diretores criam universos e estéticas tão particulares, que acabam se identificando com a própria estética da 
música para qual o videoclipe é feito. Como é o caso, por exemplo, da parceria entre Michel Gondry e Björk. Ou no caso também da parceria entre Chris Cunningham e Aphex Twin.

Alguns desses diretores não efetuaram a migração para o cinema, como é o caso de Chris Cunningham, e ficaram no ambiente do videoclipe. Outros foram fazer filmes, como Spike Jonze e Michel Gondry. No ambiente que estamos tratando, esses realizadores já não obedecem à concepção clássica cinematográfica e tampouco obedecem à lógica do vídeo. Eles apresentam outra proposta estética e narrativa, como é o caso de Michel Gondry, que insere tanto em seus videoclipes como em seus filmes elementos que dialogam com o cinema e com o vídeo, além de outras artes.

O filme "Brilho eterno de uma mente sem lembranças", de Michel Gondry, foi lançado em 2004 e é o segundo longa-metragem deste diretor. O primeiro foi "Natureza humana", de 2001. Em 2006 ele lançou "La science des rêves", ainda inédito no Brasil, e em 2008 foi lançado o filme "Be kind, rewind".

Antes de fazer seu primeiro longa-metragem, Michel Gondry já tinha desenvolvido um amplo trabalho no formato do videoclipe (principalmente os vídeos que fez com a cantora islandesa Björk) e já era conhecido por ter sido uns dos diretores que reinventaram esse meio por seu trabalho particularmente original. Fez também diversos curtas-metragens e spots publicitários, além de outros trabalhos. Michel Gondry nasceu em Versailles, na França, e optou por estudar artes em uma escola de Paris. Começou sua carreira fazendo os vídeos de sua própria banda, “Oui-Oui”, e, quando um desses vídeos exibidos na MTV foi visto por Björk, esta o chamou para dirigir seu primeiro videoclipe da carreira solo, "Human behaviour". Foi o sucesso alcançado com esses trabalhos que possibilitou a ele dirigir seu primeiro filme, "Natureza humana" (2001). Desde então, Michel Gondry tem continuado sua carreira no videoclipe e no cinema, e com o filme "Brilho eterno de uma mente sem lembranças" ganhou destaque e reconhecimento também na indústria cinematográfica (o filme concorreu a prêmios em três categorias no Globo de Ouro, ganhou o Oscar por melhor roteiro original e também um prêmio da British Academy of Film and Television Arts).

Nesse filme de Michel Gondry, vemos justamente uma maneira de tratar tanto a linguagem cinematográfica quanto os diversos elementos que nela estão inseridos, procurando uma abordagem estética com características diretamente relacionadas a seus experimentos na área do videoclipe. A estrutura lógica da narrativa, a relação com o tempo da imagem e a forma de construção da linguagem a partir de suas características expressivas foram elementos incorporados ao cinema a partir do videoclipe. A busca pela plasticidade da imagem, o uso da música, a textura, a construção poética mais do que figurativa, a sobreposição de camadas com o uso de diversos elementos como voz, palavra, sons, imagens fotográficas, objetos de cena, voz off, desenhos e cenários fazem parte dos procedimentos usados por Gondry tanto no videoclipe como no cinema. Esses elementos interagem, resignificando-se no filme e servindo aos seus propósitos narrativos e estéticos. É a forma como esse diretor particularmente usa os elementos do videoclipe no filme, explorando 
outra lógica narrativa dentro do cinema, que nos permite fazer uma análise dos procedimentos de criação identificando as incorporações e relações feitas a partir do videoclipe no cinema.

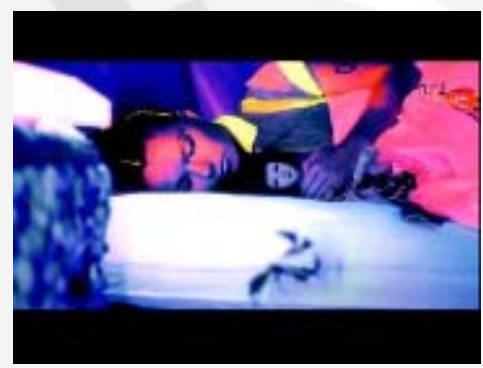

"Possibly maybe”, Stéphane Sednaoui

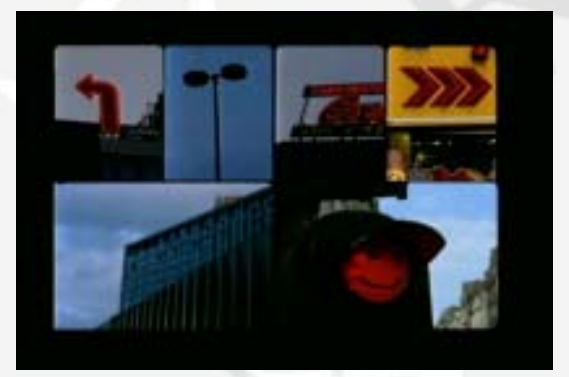

"La Tour de Pise”, Michel Gondry

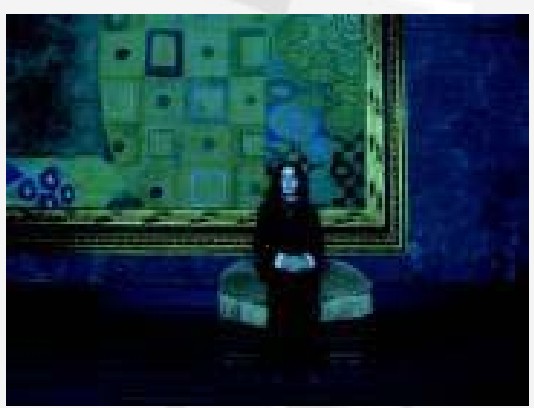

“The perfect drug”, Mark Romanek

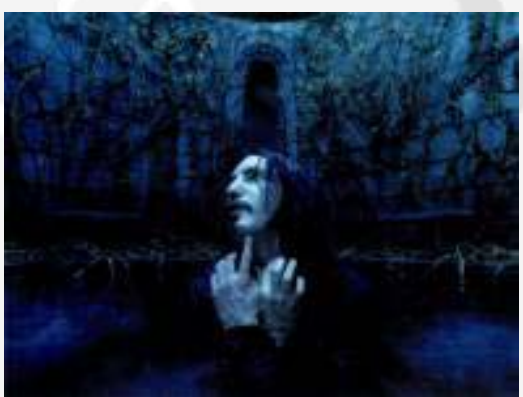

“The perfect drug”, Mark Romanek 


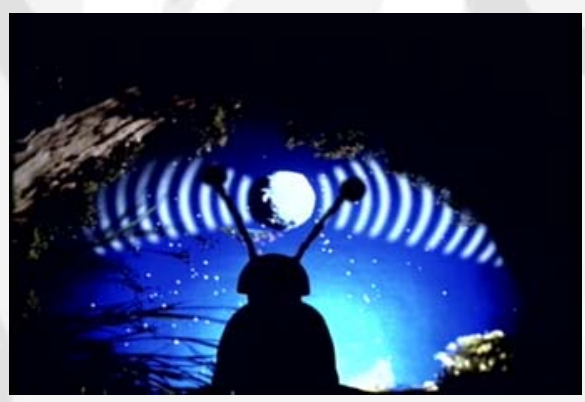

"Human behaviour", Michel Gondry

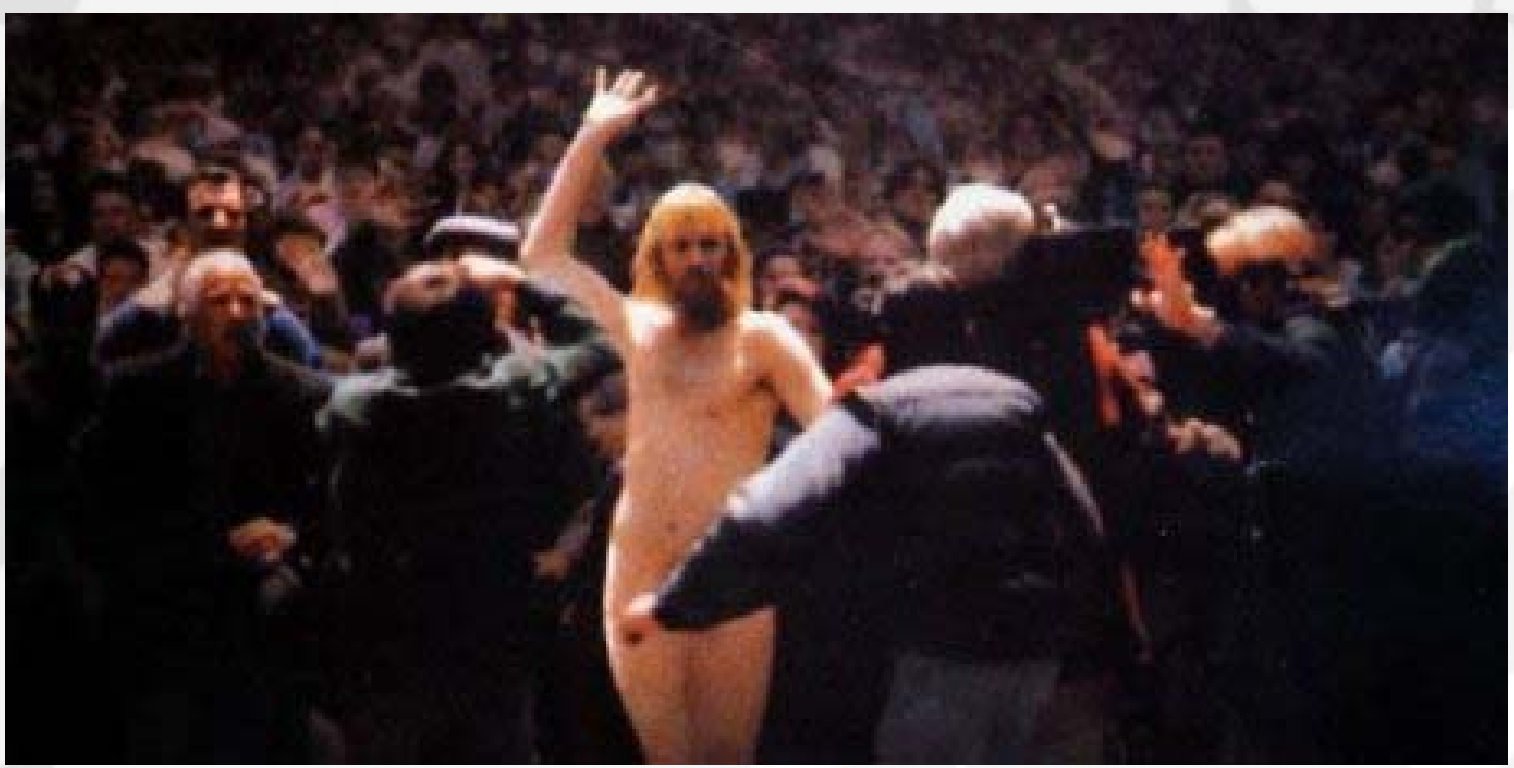

“Natureza humana”, Michel Gondry 


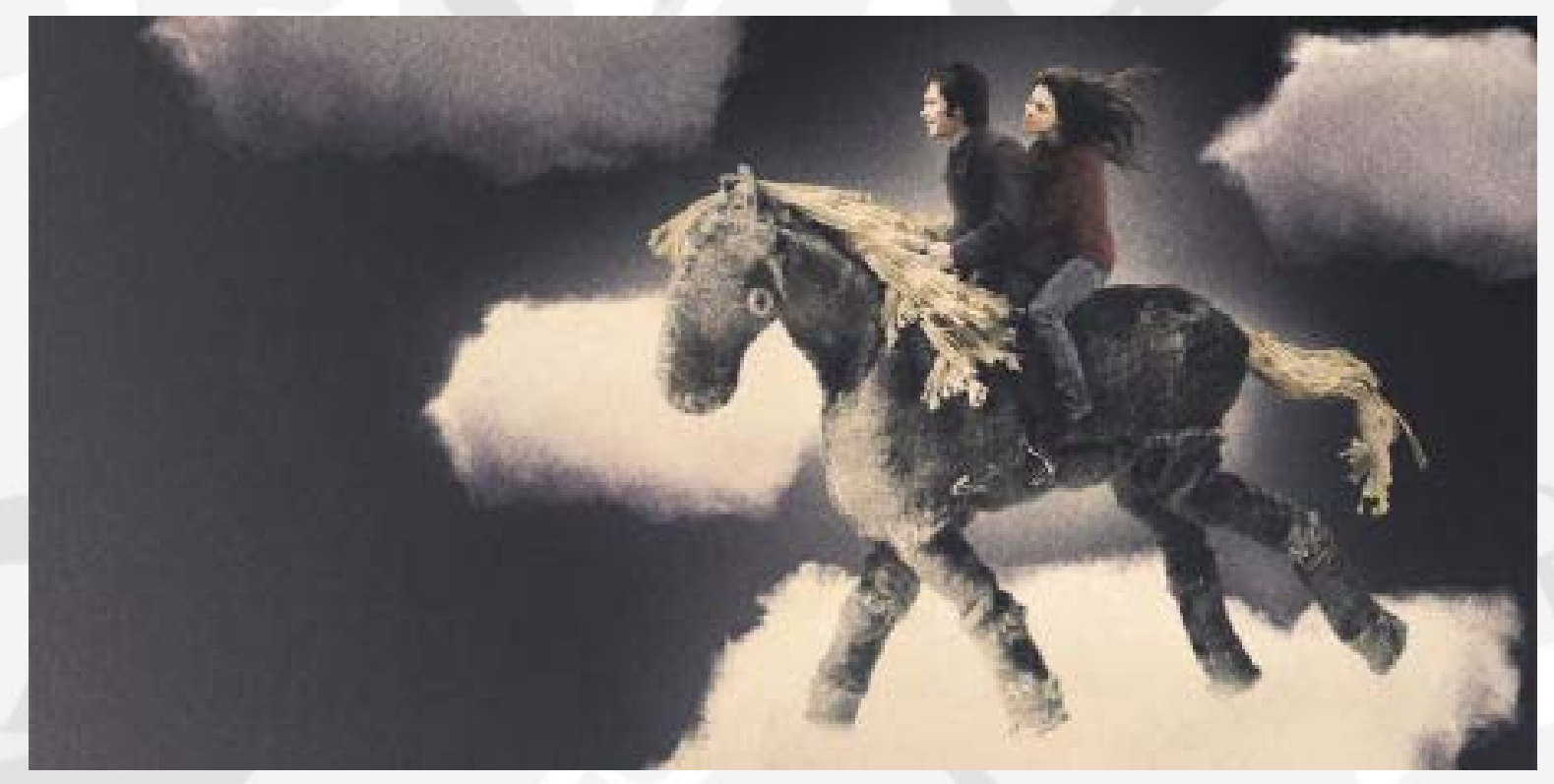

"La science des rêves", Michel Gondry

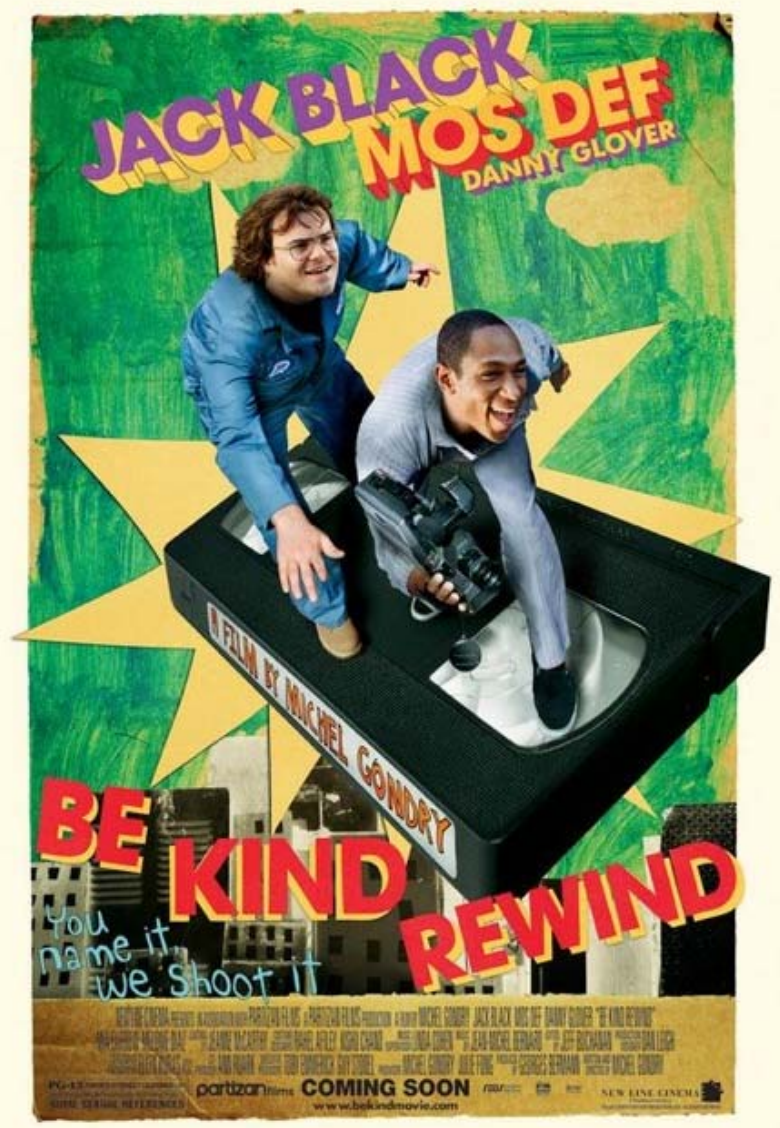

"Be kind rewind”, Michel Gondry 


\section{Referências bibliográficas}

BARBOSA, Christine Nelson de Mello. Conexões processuais no vídeo. Estudo sobre a gênese de "Love stories” de Lucas Bambozzi. Dissertação de Mestrado. Programa de Comunicação e Semiótica. PUC-SP, 1999. BARBOSA, Christine Nelson de Mello. Extremidades do vídeo. Tese de Doutorado. Programa de Comunicação e Semiótica. PUC-SP, 2004.

BELLOUR, Raymond. Entre-imagens. Campinas: Papirus, 1997.

BENTES, Ivana. "Vídeo e cinema: rupturas, reações e hibridismo". In: MACHADO, Arlindo. Made in Brasil: três décadas do vídeo brasileiro. São Paulo: Iluminuras/Itaú Cultural, 2007.

BOLTER, Jay David e GRUSIN, Richard. Remediation: Understanding New Media. Cambridge: The MIT Press, 2000.

CALVINO, Italo. Seis propostas para o próximo milênio. São Paulo: Companhia das Letras, 1990.

DELEUZE, Gilles. La imagen-tiempo - Estúdios sobre Cine 2. Barcelona: Paidós, 1987.

DELEUZE, Gilles. La imagen-movimiento - Estudios sobre Cine 1. Barcelona: Paidós, 1987.

DUBOIS, Philippe. Cinema, vídeo, Godard. São Paulo: Cosac \& Naify, 2004.

MACHADO, Arlindo. Pré-cinemas e pós-cinemas. Campinas: Papirus, 1997.

MACHADO, Arlindo. O quarto iconoclasmo e outros ensaios hereges. Contra Capa, 2001.

MACHADO, Arlindo. A televisão levada a sério. São Paulo: Senac, 2001.

MACHADO, Arlindo. Arte e mídia. Rio de Janeiro: Jorge Zahar, 2007.

MACHADO, Arlindo. Made in Brasil: três décadas do vídeo brasileiro. São Paulo: Iluminuras/Itaú Cultural, 2007.

MACIEL, Maria Esther (org.). O cinema enciclopédico de Peter Greenaway. São Paulo: Unimarco, 2004.

MERTEN, Luis Carlos. “Cinema virou arte burra”. O Estado de S. Paulo, Caderno 2, 10/07/2007.

MOURÃO, Maria Dora. “O tempo no cinema e as novas tecnologias”. In: Ciência e Cultura, v. 54, 2002.

MOLINA, Camila. “Artistas criam no território do videoclipe”. O Estado de S. Paulo, Caderno 2, 20/07/ 2007.

REZENDE, Marcelo. Ciência do sonho: a imaginação sem fim do diretor Michel Gondry. São Paulo: Alameda, 2005.

REZENDE, Marcelo e OLIVA, Fernando (orgs.). Comunismo da forma: som, imagem e política da arte. São Paulo: Alameda, 2007.

REZENDE, Marcelo. “Não gosto de ironia gosto de humor”. Folha de S. Paulo, Ilustrada, 28/01/2008.

SALLES, Cecilia Almeida. Gesto inacabado - Processo de criação artística. São Paulo: Annablume. 2001.

SALLES, Cecilia Almeida. Redes da criação: construção da obra de arte. Vinhedo: Horizonte, 2006. 


\section{Periódicos}

DIRIGIDO. Barcelona, março de 2000.

EL AMANTE. Del montaje a la fusión. Buenos Aires, julho de 2004.

EL AMANTE. La amante del volcán. Buenos Aires, fevereiro de 2001.

EL AMANTE. Un milagro con cabeza. Buenos Aires, março de 2000.

EL AMANTE. Mister Jonze. Buenos Aires, março de 2000.

POSTIF. Paris, outubro de 2004.

SIGHT AND SOUND. I forgot to remember to forget. Londres, maio de 2004.

ZETA FILMES. Entrevista Michel Gondry e Charlie Kauffman - Anthony Kaufman.

\section{Páginas de Internet}

http://www.directorslabel.com

http://comunismodaforma.zip.net

http://www.michelgondry.com

http://www.markromanek.com

http://www.youtube.com

http://www.focusfeatures.com

\section{Catálogos}

Comunismo da Forma: Som + Imagem + Tempo, A Estratégia do Vídeo Musical. Curadoria Fernando Oliva e Marcelo Rezende. São Paulo: Galeria Vermelho, 2007.

Colateral 2: Quando a Arte Olha o Cinema. Curadoria Adelina Von Fürsternberg. Colaboração: Anna Daneri e Andrea Lissoni. Projeto de Hangar Bicocca. Organização: Art for the World. São Paulo: Sesc-SP, 2008.

\section{Notas}

(1) O conceito de remediation é definido por Bolter e Grusin como "a lógica formal pela qual um novo meio reconfigura formas de medias anteriores".

(2) Christine Mello fez um amplo estudo sobre este trabalho em sua dissertação de mestrado Conexões processuais no vídeo: estudo sobre a gênese do 'Love stories' de Lucas Bambozzi (PUC-SP, 1999).

(3) Esta mostra foi realizada pela Galeria Vermelho, em São Paulo, de 20/07-04/08/2007, com curadoria de Fernando Oliva e Marcelo Rezende. Além da mostra, os curadores lançaram um livro com o mesmo nome e um blog.

(4) Para Fernando Oliva e Marcelo Rezende, o conceito de "biblioteca" é utilizado para definir o uso que o videoclipe faz de diversos elementos da cultura, atualizando-os e gerando novos significados. E assim trazendo à tona a memória do espectador. 